Hovhannes HOVHANNISYAN,

Hasmik HOVHANNISYAN,

Astghik PETROSYAN

UDC 311.21:316.6:159.9:94(479.25)

\title{
THE SPECIFICITIES OF THE PHENOMENA OF THE ARMENIAN GENOCIDE AND THE PSY- CHOLOGICAL IMPACT IN PUBLIC OPINION
}

(Sociological Survey Result Analysis)

\begin{abstract}
The research was conducted in 2015 from March 15-April 15, based on the method of formalized survey. Five hundred and sixty Yerevan citizens took part in the survey.

According to the survey the moods of reliving the pain, the hope and belief for future, optimism (91.2\%) exceed the moods of complaint, wrath, revenge and compensation (88.2\%) and the moods of regret, pain, depression and declining moods (76.2\%).

However, as the results of the study come to prove, the mosaic of the public perception and the psychological reflection of the Armenian genocide as a phenomenon is very sophisticated. In the above mentioned categories the included components are intertwined and bound together. The moods and feelings included in those groups appear next to each other alternating quite fast.
\end{abstract}

Key words: genocide committed against Armenians, public perception, moods, feelings and positions, ways of overcoming the consequences of the genocide.

(I)

\section{THE METHODOLOGICAL BASES OF THE STUDY}

\section{The Essence of the Fundamental Problem}

Public opinion is a unique sphere of transformations which is part of the social system with the respective moods, positions, stereotypes and dynamics. The experience testifies that the projects and policy which are being implemented often lead to mistakes and unwanted results, bring forth the public's mistrust and discontent if the public opinion regarding vital problems isn't examined and the existing dynamics aren't taken into consideration. Meanwhile the policy and tactics based on the stud- ies of public opinion have a desirable productivity and a positive consequence.

The genocide committed against Armenians living in the areas of historical Armenia and Ottoman Empire has left an indelible trace in the mentality and public consciousness of the 20-21 centuries Armenian people. Memories and the aftermaths of Armenian genocide have become a vital part of the collective identity of Armenians.

International recognition, condemnation of the Armenian genocide and the factor of elimination of its consequences, plays a crucial role in the agenda of the foreign policy of the Republic of Armenia. In this regard, it is essential to reveal and examine the viewpoints formed in public opinion regarding this phenomenon. 
The purpose of the study

To bring forth the spectrum of moods and positions existing in the public opinion regarding the fact of the Armenian Genocide planned and committed by the authorities of the Ottoman Empire in the 20th century and the spectrum regarding the steps of easing and eliminating its consequences.

To prepare an analysis based on the received data which might be actionable for the official bodies that pursue a policy in the sphere.

\section{The problems of the study}

To bring forth the spectrum of perception of the Armenian Genocide, the moods, emotive responses and reasonable viewpoints regarding this historical event among the citizens of Yerevan.

To study the positions of the public opinion on a number of different options discussed in the political circle regarding the elimination of the consequences of the genocide.

To evaluate the positions regarding the genocide and the countries, political bodies which play or have played any role in the process of its recognition and condemnation.

\section{The target audience and tools of the study}

The study has been implemented in Yerevan (among Yerevan citizens). The choice has been made up in 2011 based on the census with the method of multivariate lamination. The conglomerate of the target audience has been formed according to

\section{Gender}

2. 4 age groups: $18-30,31-45,46-60,61$ and older and educational
3. Levels: incomplete secondary, secondary, secondary vocational and high education; divided into 24 groups with the principle of proportional representation.

560 Yerevan citizens have taken part in the survey. The sociological study has been implemented with the method of formalized interviews. The initial work of the collection of the sociological information was done within March 15-April 15 of 2015.

(II)

\section{WHAT MOODS AND FEELINGS DO THE RECOLLEC- TION OF ARMENIAN GENOCIDE \\ AND THINKING ABOUT IT AWAKE AMONG THE RE- SPONDENTS?}

The participants were presented probable moods and feelings and they were offered to mark the ones they experience and how much they do that while speaking about the Armenian Genocide.

The moods and feelings offered in the list were grouped in 3 categories.

Feelings of:

1. regret, pain, depression, declining moods,

2. complaint, wrath, revenge, struggle for the compensation,

3. reliving, belief and hope for the future, optimism.

The average indicator for the manifestation of the feelings and moods of the first group was $76.2 \%$. The feelings and moods of the second group are more expressive. It is of note that the moods of the third group reliving the catastrophe, belief and hope for the future, optimism) are even more expressive $-91.2 \%$. See in the graph.

Graph 1: A comparative table of the existing moods regarding the Armenian Genocide in the public opinion. 


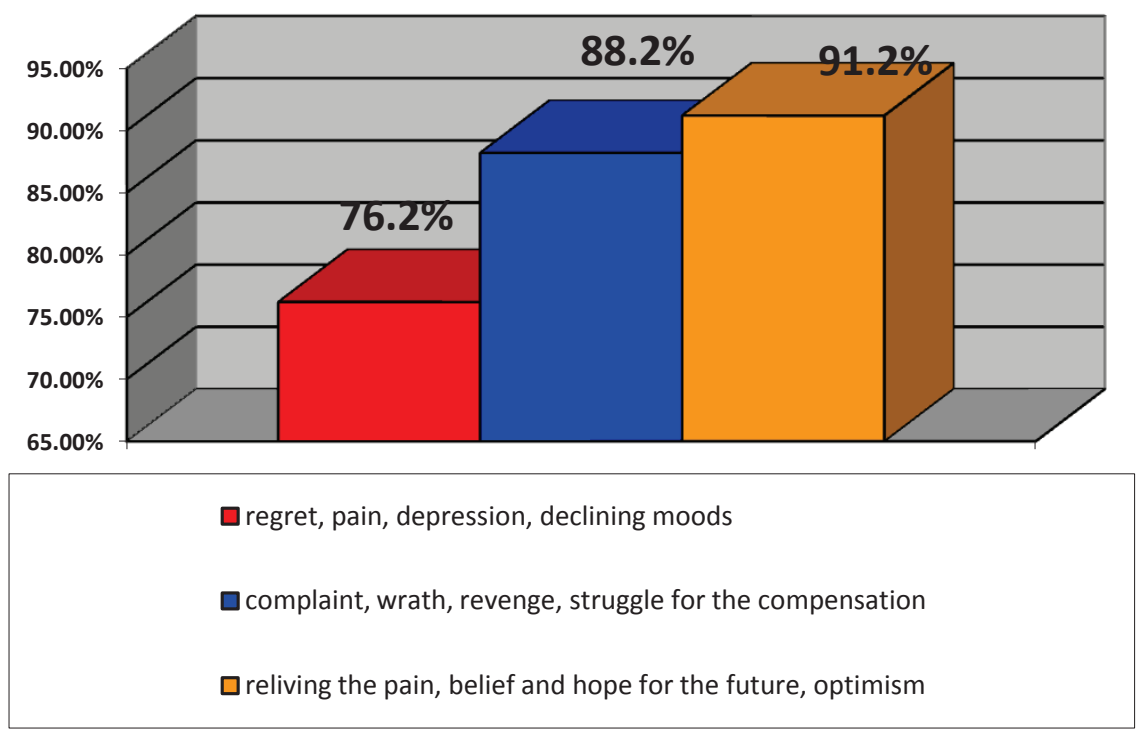

However, as the results of the study come to prove, the mosaic of the public perception and the psychological reflection of the Armenian genocide as a phenomenon is very sophisticated. In the above mentioned categories the included components are intertwined and bound together. The moods and feelings included in those groups appear next to each other alternating quite fast.

The feeling of regret and pain was on the first place making up $96.4 \%$. The $23.4 \%$ of the participants experience this feeling considerably much, while $73 \%$ have even stronger feelings. Moreover, the existence and strength of this feeling is not only nearly the same for both men and women but also for all the age groups. It increases a bit with the simultaneous rise of the educational qualification.

- The ones with incomplete secondary education experience this feeling - 95\%.

- The ones with secondary, secondary vocational education $-95 \%$.

- The ones with incomplete high and high education - 98.6\%.

The second one is the feeling of hatred against those who organized and committed genocide. This has been marked by $95 \%$ of the participants (16.1\% experience this feeling considerably much, while $78.9 \%$ even stronger feelings). Moreover, the indicator of this feeling is nearly the same for all the age groups. It decreases slightly with the simultaneous increase of the educational qualification.

- The ones with incomplete secondary education experience this feeling - $100 \%$.

- The ones with secondary, secondary vocational education $-95.3 \%$

- The ones with incomplete high and high education - 94.0\%

The third one is the feeling of endurance and the determination to live despite the catastrophe of genocide $-93.4 \%$. This mood is nearly the same for both males and females for all the age groups and it rises slightly with the simultaneous increase of the educational qualification. (Among the participants with incomplete secondary education it makes up $90 \%$. Among those with secondary, secondary vocational education - 93.8\%.Among the ones with incomplete high and high education -94.0\%).

On the fourth place it is the feeling of determination to get the loss back at least partly-92.9\%.

This mood is a bit more noticeable among older generation (40-60 year old) respondents $-94.1 \%$. Among comparatively young people (18-45) it makes up 91.2\%.

Based on intensity on the fifth place are the moods of struggle for demand and compensation 92.0\%. This mood is more noticeable among the 
representatives of the young generation (18-45), than among older people (46-61) -90.2\%.

On the sixth place is the mood of improving and making Armenia powerful with everyday work90.5\%. It is more expressed among women (92.2\%) with $5.3 \%$ than among men (87.6\%).

The seventh is the feeling of wrath and revenge $-88.8 \%$. This feeling is more expressed among older generation (46-61 and older people) - 90.6\%, than among younger people (18-45 year old) $87.3 \%$.

On the eighth place are the moods of hope and optimism $-87.9 \%$. The indicator of the existence of these moods is nearly the same for women and men and it is expressed more noticeably among the young (18-45 year old) - $91.2 \%$ than among older people (46-61 and older) $-83.9 \%$. The indicator of the mood of hope and optimism sees some rise also with the simultaneous increase of the educational qualification. Among the respondents with incomplete secondary education it makes up $85.0 \%$, among the ones with secondary and secondary vocational education it is $85.4 \%$, while among the participants of the survey with high education it is 91.7\%.

The ninth one is the wish to speak to others (to the people of other nationlities) about Armenian's pain $-77.0 \%$. $79.0 \%$ of women and $74.4 \%$ of men have chosen this. Moreover, with the rise of age, the number of people with this mood increases (among people at the age of 18-30 it makes up $72.0 \%$, among $31-45$ year old people $-76.1 \%$, 46-60
- 78.1\%, and among 61 year old and older people it is $84.3 \%)$.

The tenth one is hesitation and alarm for the future $-73.1 \%$. This is comparatively more noticeable among the older generation (46-61 and older) $-76.4 \%$ than among the young (18-45) $-70.3 \%$. This mood is expressed more considerably among the participants with a law educational qualification (incomplete secondary) $-80.0 \%$.

The eleventh one is the feeling of being a victim and persecuted $-68.4 \%$. This feeling is more considerably expressed among $34.6 \%$ of the participants. With its volume (altogether - 73.1\%) and intensity (more expressed among 50\%) this is more considerably expressed among 61 and older people. For instance, among people at the age of 18-30 this feeling is noticeable generally in $68.3 \%$ and more considerably $31.7 \%$.

The list of moods connected to the moods and feelings of genocide is concluded by the feeling of depression and disappointment - 66.8\%. With the intensity of manifestation it is again on the last place in the row of feelings and moods. This feeling considerably exists among the $28.9 \%$ of the participants of the survey. Moreover this feeling is more considerably expressed among people at the age of 61 and older- $85.9 \%$ and the most considerably among $36.1 \%$ of them. For the comparison, it is of note that this indicator makes up $23.8 \%$ among 18 30 year old people.

Graph 2: A table of the existing moods and feelings in the public opinion regarding the Armenian Genocide. 


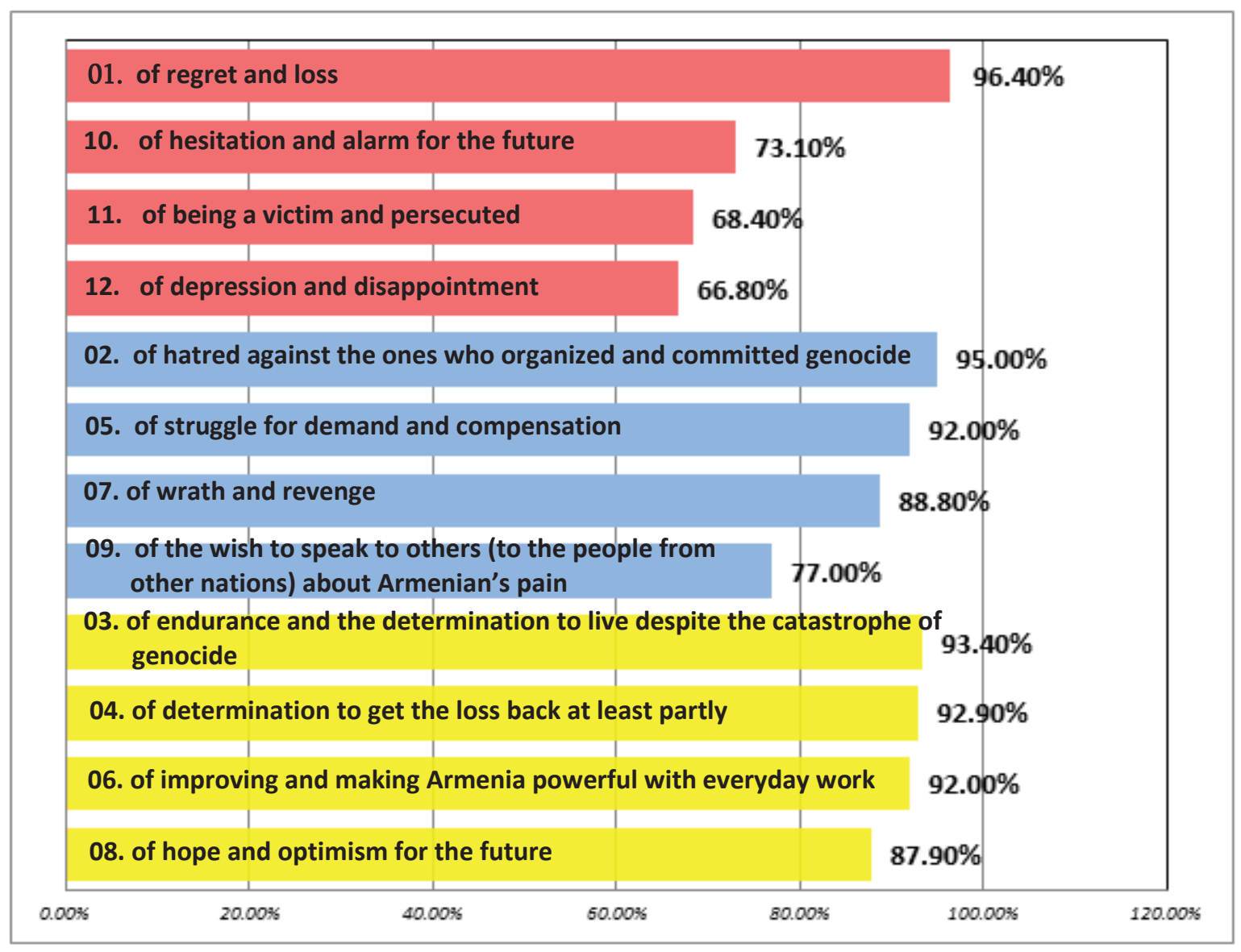

(III)

THE VARIETIES OF THE ELIMINATION OF THE CONSEQUENCES OF THE GENOCIDE ACCORDING TO THE PARTICIPANTS OF THE SURVEY

The participants of the survey were offered to choose from 10 options which are being studied in political and experimental circles, and also from the ones which appear in Mass Media choosing the most realistic and useful utmost 2 options.

On the first place is getting the areas of Historical Armenia back $-62.7 \%$. The number of the supporters of this option is greater among 18-30 year old people (67.1\%) and it decreases gradually with the simultaneous rise of the age scale (30-45 year old people $-62.7 \%$, 46-60 year old people-61.0\%, 61 and older $-58.3 \%$ ).

On the second place is the recognition and condemnation of the fact of Genocide by Turkey committed against Armenia $-48 \%$.
The third option according to the public opinion can be the resettlement of the victims, their relatives and heirs in the historical homeland $-27 \%$.

The rest of voting result is as follows:

4. The recognition of the Republic of Karabakh by Turkey-24.6\%.

5. The provision of a material and financial compensation to the victims' heirs $-24.3 \%$.

6. The provision of a favorable location as a territorial compensation for the Armenian side, particularly provision of the exit to the Black See $24.1 \%$ The supporters of this option are more common among men -28.4, (among women it is - 20.6) and among the respondents with high education $26.1 \%$ and among people older than 60 it is $25.9 \%$

7. The provision of a financial compensation to the Armenian side (the republic, Panarmenian organizations) from Turkey $-19.1 \%$. 
8. The definition of some privileges (business, tax etc.) in Turkey for Armenians $-11.3 \%$.

9. The implementation of some historical, cultural, propaganda projects which would shed off the denying and anti-Armenian moods $-11.3 \%$.

10.The implementation of propaganda, cultural projects for the Armenian society which would shed off the psychology of a victim.

THE ATTITUDE OF DIFFERENT COUNTRIES, POLITICAL BODIES TOWARDS ARMENIA AND ITS PROBLEMS ACCORDING TO THE PUBLIC OPINION AND THE ATTITUDE OF OUR CITIZENS TOWARDS THESE BODIES

The fact that the international recognition and condemnation of the Armenian genocide is a question of vital importance to the foreign policy of the Republic of Armenia means close relationships and considerate work with different international organizations and countries.

What is the attitude of different countries and political organizations towards Armenia and its problems according to Yerevan citizens?

With the positive attitude the first country on the list of 24 organizations and countries suggested by the participants of the survey is France. $81.1 \%$ of the respondents have chosen this option.

On the second place is Russia $-68.6 \%$.

The third one is Greece - $55.0 \%$.

On the fourth place is the United Nations. $51.6 \%$

The fifth one is Italy $-47.3 \%$

Among ten countries and organizations with a positive attitude towards Armenia and its problems the participants of the survey also included: Syria $43.2 \%$, Uruguay $-42.9 \%$, Commonwealth of Independent States $-41.8 \%$, Georgia - 4.1, Germany $40.5 \%$.

Among the countries with a negative attitude towards Armenia and its problems Azerbaijan and
Turkey are in the lead with $96.1 \%$. The second one is the Islamic Republic - 49.6\%. The third one is the USA - 22.1\% (Though 33.1\% of respondents have chosen the USA as a country with a positive attitude towards Armenia). The fourth one is Kazakhstan $13.9 \%$. The fifth one is Hungary with $22.7 \%$.

What is the attitude and position of respondents towards different countries and organizations?

The most favorite one for the respondents is again France. $82.5 \%$ of the respondents have expressed their positive attitude towards this country. The indicator ${ }^{1}$ of the mutuality of the positive attitude in case of France according to the answers given by respondents from Yerevan is 0.99 .

The second one is Russia- $73.2 \%$. The indicator of mutuality is a bit less -0.94 in comparison to France. This means, according to the survey they have a more positive attitude towards those countries $-73.2 \%$ than the latest towards Armenia and its problems $-68.6 \%$. Among the first ten countries and organizations which gained the goodwill and positive attitude of the respondents are also included Italy - 63.8\% (the indicator of the mutuality of the positive attitude -0.74 ), Greece $-60.7 \%$ (the indicator of the mutuality of the positive attitude 0.64), Germany $-56.1 \%$ (the indicator of the mutuality of the positive attitude - 0.72), The USA $48.9 \%$ (the indicator of the mutuality of the positive attitude -0.64 ), Belarus $-45.2 \%$ (the indicator of the mutuality of the positive attitude -0.79 ), The UN $-47.7 \%$ (the indicator of the mutuality of the positive attitude -1.1 ), Georgia $-44.8 \%$ (the indicator of the mutuality of the positive attitude -0.92), Commonwealth of Independent States- $41.6 \%$ (the indicator of the mutuality of the positive attitude 1.0).

\footnotetext{
${ }^{1}$ Shows the relation of the indicator of expressing the positive attitude of that country to the indicator of the respondents' positive attitude towards that country regarding Armenia and its problems according to the participants of the survey.
} 
Azerbaijan leads the list of countries which received a negative attitude from the participants of the survey. $92.2 \%$ of the respondents have expressed such an opinion. On the second place is Turkey - 90.4\%. The third place - Islamic Republic $49.1 \%$.
The facts received through the public opinion should not be perceived as expertise. Very often there are essential differences between them.

However, acquired statistics based on public opinion regarding such vital problems create a huge foundationfor further scientific studies, research and analysis, as well as increase of productivity of similar projects and policy in a particular sphere. 